\title{
Orta tabakası kompost atığı ilaveli yongalevhaların vida tutma gücü ve ısı iletkenlik değerlerinin belirlenmesi
}

\section{Determination of screw holding and thermal conductivity values of core layer compost waste additive particleboard}

\author{
Halil ibrahim ŞAHIN, Mesut YALÇIN, Nurbanu YAGLICA
}

Düzce Üniversitesi, Orman Fakültesi, Orman Endüstri Mühendisliği Bölümü, Düzce, Türkiye

\author{
Eser Bilgisi / Article Info \\ Araştırma makalesi / Research article \\ DOI: 10.17474/artvinofd.320521 \\ Sorumlu yazar / Corresponding author \\ Halil ibrahim ŞAHIN \\ e-mail: \\ halilibrahimsahin@duzce.edu.tr \\ ORCID: 0000-0003-2247-9895 \\ Geliş tarihi / Received \\ 12.06.2017 \\ Düzeltme tarihi / Received in revised form \\ 14.08.2017 \\ Elektronik erişim / Online available \\ 10.09.2017 \\ Anahtar kelimeler: \\ Yongalevha \\ Üre formaldehit tutkalı \\ Kompost atığı \\ Vida tutma gücü \\ Isı iletkenlik değeri \\ Keywords: \\ Particleboard \\ Urea formaldehyde adhesive \\ Compost waste \\ Screw holding \\ Thermal conductivity
}

\begin{abstract}
Özet
Bu çalışmada laboratuvar ortamında odun ve kompost atıklarından üre formaldehit tutkalı kullanılarak üretilen yongalevhaların vida tutma gücü ve ısı iletkenlik değerleri araştırılmıştır. Bu amaçla, dış tabakada sadece endüstriyel odun yongası kullanılır iken orta takada ise belli oranlarda kompost atığı ve endüstriyel odun yongası karışımı kullanılmıştır. Levha yoğunluğu $0.630 \mathrm{~g} \mathrm{~cm}^{-3}$ olan, 50x50x1.8 cm boyutlarında, \%50'lik üre formaldehit tutkalı kullanılarak yatık preslenmiş yongalevhalar üretilmiştir. Levhaların yüzeylerine ve kenarlarına dik vida tutma gücü ile ısı iletkenlik değerleri belirlenmiştir. Kompost atığı ilavesinin, yongalevhaların yüzeyine dik ve paralel yöndeki vida tutma gücü değerleri üzerine etkili olduğu saptanmıştır. Levha gruplarına ait ısı iletkenlik değerleri $0.086-0.120 \mathrm{~W} \mathrm{~m}^{-1} \mathrm{~K}^{-1}$ arasında değiştiği tespit edilmiştir. İzolasyon levhası olarak en iyi sonuçlar orta tabakasında \%100 kompost atığı kullanılan yongalevhalarda elde edilmiştir.
\end{abstract}

\begin{abstract}
In is study, screw holding and thermal conductivity values of particleboard produced from wood and compost waste were investigated under the laboratory conditions. To that end, the compost waste and industrial wood chips were used to a certain extent in the core layer while only industrial wood

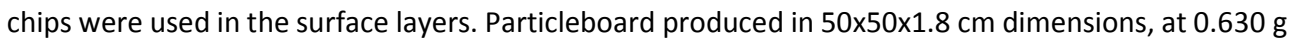
$\mathrm{cm}^{-3}$ density with using $50 \%$ urea formaldehyde adhesive. The surface and edge vertical screw holding and thermal conductivity of particleboards were determined. It was stated that addition of compost waste affected the surface and edge vertical screw holding of particleboard. The thermal conductivity values belonging to particleboard were found to vary between $0.086-0.120 \mathrm{~W} \mathrm{~m}^{-1} \mathrm{~K}^{-1}$. The best results for the insulation board were obtained from the particleboard using $100 \%$ compost waste in the core layer.
\end{abstract}

\section{GíRiş}

Son yıllarda orman alanlarında meydana gelen tahribatlar ve çölleşmenin, küresel ısınma, biyolojik çeşitlilik ve odun verimliliği üzerine etkileri toplumları endişelendirmektedir. Bu kaygıların bir sonucu olarak, ormancılık uygulamaları değişmekte ve odun lifi eldesinde problemler ortaya çıkmaktadır. Son zamanlarda bu durum özellikle Amerika ve Avrupa'da ortaya çıkmıştır. Özellikle hammadde odun açığının kapatılması için alternatif tarımsal bazlı yeni hammaddeler üzerinde çalışmalar yapılmaktadır. Ayrıca birçok ülkede ormanlardan üretilen odun, ihtiyaç duydukları yakacak, endüstriyel ve levha odununu karşllayacak seviyede değildir. Fakat bu ülkelerin çoğu, yıllık bitkilerin tarımsal atıklarından oluşan diğer lignoselülozik malzemelere fazlası ile sahiptirler (Strangh 1993; Youngquist 1993; Grigoriou ve Ntalos 2001).

Mantarın beslenmesi için çeşitli organik maddelerin ayrıştırılması ve bazı besin elementlerin eklenmesi sonucu elde edilen ortama kompost denilmektedir. Kompostlar genellikle at gübresi ile buğday sapı, çeltik ve çavdar sapı, kepek, melas, parçalanmış mısır koçanı gibi lifsel özellik taşıyan, kolay ve ucuz olarak elde edilebilen malzemelerden üretilmektedir. Geçtiğimiz yarım yüzyılda, dünya kültür mantarı üretiminde hızlı bir büyüme yaşanmıştır. 1961 yılında 495.127 ton olan mantar üretim miktarı 2013 yılında 9.926.966 tona ulaşmıştır (Eren ve Pekşen 2016). Kültür mantarı verimi, kullanılan kompost 
ağırlığının yaklaşık \%20'si olduğu düşünüldüğünde, Dünya genelinde her yıl milyonlarca ton kompost atığı meydana geldiğini söylemek mümkündür. Tüik verilerine göre Türkiye'deki kültür mantar üretimi 2015 yılında, yaklaşık 40000 ton olarak gerçekleşmiştir (Anonim 2016a). Bu üretimin 2017 yılında daha artarak devam edeceği düşünülmektedir. Bu açıdan bakıldığında ülkemizde her yıl yaklaşık olarak 160000 tonun üzerinde kompost atığı oluşmaktadır. $\mathrm{Bu}$ atığın levha endüstrisinde değerlendirilmesi ile hem çevre açısından, hem de levha üretim maliyetlerinin düşürülmesi için bir fırsat oluşturacaktır. Mantar üretimi sonrası herhangi bir ekonomik değeri olmayan kompost atıkları, levha üretiminde değerlendirilmesi ile mantar üreticileri için alternatif bir gelir kaynağı oluşturacaktır.

Yongalevhadan yapılmış ahşap esaslı ürünler (mobilya, dolap, masa, sıra vb.) genellikle önemli yüklere maruz kalırlar. Bu nedenle yongalevhaları birleştirmek için çelik dişli bağlantı elemanları kullanılmaktadır. Bu bağlantı elemanlarının direnci ahşap esaslı malzemelerin mukavemetinden en az 10 kat daha yüksektir. Çelik vida ile yapılan birleştirmede meydana gelecek aşırı yüklenme sebebi ile kopma ahşap esaslı levhadan meydana gelmektedir. Bu yüzden birleştirme kuvveti, vidadan ziyade ahşap esaslı panel levhaların dayanımlarına göre belirlenir (Smardzewski ve Klos 2011).

Herhangi bir malzemenin ISı (termal) iletkenliği ısı iletim katsayısı ile belirlenmektedir. Odunun ısı iletkenliği de gözenekli yapısından dolayı düşüktür. Ancak ağaç malzemenin Isı iletkenliği değeri sabit değildir. Çünkü odunu meydana getiren hücre elemanlarının yapısı, büyüklükleri, çeper kalınlıkları, birim hacimdeki madde miktarı değişkenlik göstermektedir. Ayrıca ısı iletkenliği, üretilen levhanın yoğunluğu, türü, kalınlığı, rutubeti ve üretim yöntemi, yonga boyutu ve geometrisi, odunun içerdiği hava, su ve yabancı madde miktarından etkilenmektedir (Cosereanu ve ark. 2014; Özdemir ve ark. 2013; Yu ve ark. 2011; Sonderegger ve Niemz 2009; Örs ve Şenel 1999).

Mobilya endüstrisinde yaygın olarak kullanılan yonga levha, MDF, werzalit ve kayın odununun (Fagus orientalis spp.) üzerinde bağlantı elemanı olarak seçilen 3 farklı vida tipinin yüzeye paralel ve dik yönlerde tutma kabiliyetleri araştırılmıştır. Deneyler sonucunda yüzeye paralel ve dik yönde en yüksek vida tutma gücü masif kayın malzemede elde edilmiş, bunu sırasıyla werzalit, yonga ve MDF levhalar izlemiştir (Örs ve ark. 1998).

Farklı kalınlıklarda ve $0.700 \mathrm{gr} \mathrm{cm}^{-3}$ yoğunlukta üretilmiş yongalevhaların bir kısmının yüzeyi melamin emdirilmiş kâğıtlarla kaplanmıştır. Bu levhaların yüzeyine ve kenarlarına dik yönde vida tutma gücü tespit edilmiştir. Kalınlık artışının vida tutma gücünü olumsuz etkilediği, yüzeyi melamin emdirilmiş kâğıtlarla kaplı levhaların ise kaplanmamışlara göre daha yüksek vida tutma gücü verdiği ifade edilmiştir (Nemli ve Kalaycıoğlu 1999). Bektaş ve ark. (2002) üre formaldehit tutkalı kullanarak \%100 Ayçiçek saplarından ürettikleri genel amaçlı yonga levhaların teknolojik özelliklerini incelemişlerdir. Denemeler sonucunda vida tutma gücü değerlerinin 447$796 \mathrm{~N}$ arasında değiştiği belirtilmiştir. Yongalevha üretiminde kullanılan tutkal miktarının artışına bağı olarak, levhalara ait vida tutma gücünün de arttığ belirtilmektedir. Yine farklı presleme yöntemlerinin, üre formaldehit tutkalı ile üretilmiş yonga levhaların bazı teknolojik özelliklerine etkisi incelenmiştir. Çalışma sonuçları, pres çeşidinin yongalevhaların teknik özellikleri üzerinde etkilerinin anlamlı olduğunu göstermiştir. Klasik sistemle üretilen yongalevhaların yüzeye dik vida tutma gücü, sürekli sistem levhalarına oranla daha yüksek bulunmuştur (Nemli ve ark. 2004). Farklı bir çalışmada kayın, kavak ve okaliptüs odunlarından üretilmiş kontrplakların yüzey ve kenarlarından vida tutma gücü belirlenmiş, kayın kontrplakların diğer levhalara göre daha yüksek vida tutma gücü verdiği ifade edilmiştir (Bal ve ark. 2015).

Örs ve Şenel (1999) farklı ahşap ve ahşap kökenli malzemelerin ısı iletkenlik katsayılarını \%12 rutubette ve doygun halde belirlemişlerdir. Sonuç olarak hava kurusu halde ISı iletkenlik değerleri; yatık yongalı levhalarda $0.207, \mathrm{MDF}^{\prime}$ de ve 0.232 , $\mathrm{HDF}^{\prime}$ de ise $0.263 \mathrm{~W} \mathrm{~m}^{-1} \mathrm{~K}^{-1}$ olarak bildirilmiştir. Çam ve kayın liflerinden üretilen yüksek yoğunluklu lif levhalar (HDF), farklı oranlarda yanmayı geciktirici kimyasallar ile muamele edilmiş ve ısı iletkenlik katsayılarındaki değişiklikler incelenmiştir. Kontrol örnekleri ile karşılaştırıldığında, yanmayı geciktirici 
kimyasal maddelerin katılım oranına bağlı olarak ISI iletkenlik katsayısı artmıştır. Çalışmada en yüksek ıSI iletkenlik değeri $\left(0.2815 \mathrm{~W} \mathrm{~m}^{-1} \mathrm{~K}^{-1}\right) \% 9^{\prime}$ luk borik asit uygulamasında elde edilmiştir (Özdemir ve ark. 2013).

Bu çalışmada, oduna alternatif bir hammadde olarak kültür mantarı üretiminde oluşan kompost atıkları yongalevhanın orta tabakasına farklı oranlarda ilave edilerek üretimler gerçekleştirilmiştir. Çalışmanın amacı; orta tabakası kompost ilaveli üretilmiş yonga levhaların farklı yönlerdeki vida tutma gücü ve ISI iletkenlik değerlerinde meydana gelen değişimlerin belirlenmesidir. Aynı zamanda yongalevha üretiminde kullanılan odun sarfiyatının azaltılarak, hem levha üretim maliyetlerin azaltılmasını sağlamak hem de yeni bir hammadde kaynağı olarak kompost atığını değerlendirmektir.

\section{MATERYAL ve YÖNTEM}

\section{Materyal}

\section{Kompost atığı}

Levha üretiminde kullanılan kompost atıkları, Velioğlu Tavukçuluk ve Kültür Mantarı Ltd. Şti. ait kültür mantarı üretim atölyesinden temin edilmiştir. Kültür mantar üretimi sonrası ortaya çıkan atıklar Şekil 1'de görüldüğü gibi poşetler içerisinde mantar atölyesinden alınarak laboratuvarlara getirilmiştir. Öncelikle kompost üzerindeki mantar örtü toprağı uzaklaştırılmıştır. Yüksek oranda rutubet içeriğine sahip kompost atıkları açık alanlara serilerek, rutubet içeriğinin düşürülmesi sağlanmıştır.

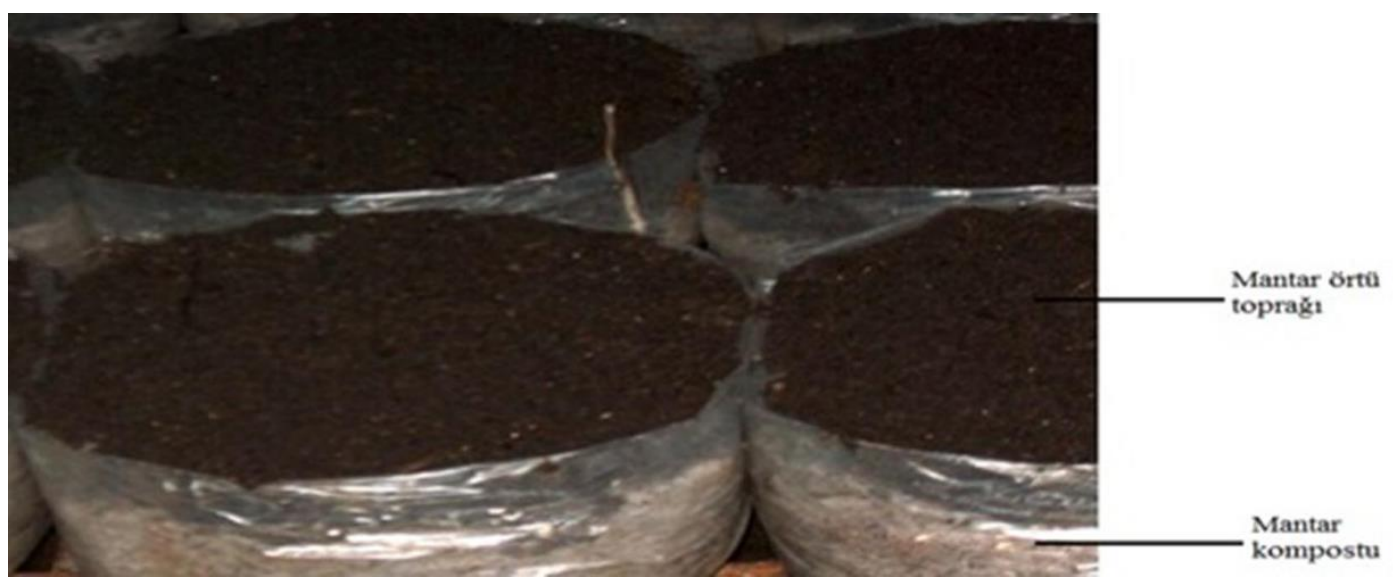

Şekil 1. Kültür mantarı kompostu (Özdemir, 2010).

\section{Endüstriyel odun yongası}

Endüstriyel odun yongaları, özel bir levha fabrikasından temin edilmiştir. Yonga içeriği, \%25 oranında ladin odunu, \%35 oranında çam odunu, \%15 oranında meşe odunu, \%15 oranında kavak kapak tahtası ve \%10 testere talaşından oluşmaktadır. Levha üretiminde üst ve alt tabaka tamamen endüstriyel odun yongası karışımından üretilir iken, orta tabakada ise endüstriyel odun yongası ile belli oranlarda karıştırılan kompost atığı yongası kullanılmıştır. Endüstriyel odun yongaları fabrikadan, dış ve orta tabakalar için üretime uygun rutubette temin edilmiştir.

\section{Yöntem}

\section{Deneme levhalarının üretimi}

Deneme levhalarının üretiminde, katı madde miktarı \%49.86, formaldehit/üre mol oranı 1.14, $\mathrm{pH}^{\prime} \mathrm{sı} 8.3$, jelleşme süresi 75 sn, depolama süresi 90 gün olan üre formaldehit tutkalı, sertleştirici olarak katı madde oranı \%33 olan amonyum klorürden faydalanılmıştır. Endüstriyel odun yongaları özel bir fabrikadan levha üretimine hazır boyutlarda ve rutubette temin edilmiştir. Kompost atıkları ise kaba ve ince yongalama işlemlerinden sonra laboratuvar tipi bir etüvde $105^{\circ} \mathrm{C}^{\prime} \mathrm{de}$ yaklaşık \%1-3 rutubete kadar kurutulmuştur. 10.5 mm'lik elekten geçip $2.1 \mathrm{~mm}$ 'lik elek üzerinde kalan kuru yongalar levhaların orta tabaka üretiminde kullanılmak 
üzere tasnif edilmiştir. Tam kuru yonga ağırlığına oranla dış tabaka için \%11, orta tabaka için ise $\% 8$ oranında üre formaldehit tutkalı kullanılmışır. Hazırlanan tutkal çözeltisine sertleştirici olarak, kuru yonga ağırlığına göre \%1 oranında \%33'lük amonyum klorür ilave edilmiştir. Deneme levhalarına ait üretim kombinasyonları Çizelge 1 'de verilmiştir.

Çizelge 1. Farklı kombinasyonlarda üretilen deneme levhaları.

\begin{tabular}{cccc}
$\begin{array}{c}\text { Levha } \\
\text { Türü }\end{array}$ & $\begin{array}{c}\text { Dış tabakalara ait } \\
\text { yonga oranı (\%) }\end{array}$ & $\begin{array}{c}\text { Orta tabakaya ait yonga oranı } \\
\text { (\%) }\end{array}$ \\
\cline { 2 - 4 } & $\begin{array}{c}\text { Endüstriyel odun } \\
\text { yongası }\end{array}$ & $\begin{array}{c}\text { Kompost } \\
\text { atığı }\end{array}$ & $\begin{array}{c}\text { Endüstriyel } \\
\text { odun yongası }\end{array}$ \\
A Grubu & 40 & 0 & 60 \\
B Grubu & 40 & 5 & 55 \\
C Grubu & 40 & 10 & 50 \\
D Grubu & 40 & 20 & 40 \\
E Grubu & 40 & 30 & 30 \\
F Grubu & 40 & 40 & 20 \\
GGrubu & 40 & 50 & 10 \\
H Grubu & 40 & 60 & 0
\end{tabular}

\section{Levha taslağının hazırlanması}

Levha taslağının hazırlanmasında $55 \times 55 \mathrm{~cm}$ boyutlarındaki paslanmaz çelikten yapılmış pres sacları kullanılmıştır. Yongaların levhalara yapışmasını engellemek için yoga ile levhaların arasına yanmaz yağlı kağıt yerleştirilmiştir. Levha kalınlıkları, $18 \mathrm{~mm}$ kalınlığındaki çelik kalınlık takozları kullanılarak ayarlanmıştır. Levha yoğunluğu $0.630 \mathrm{gr} \mathrm{cm}^{-3}$ olarak belirlenmiştir. Levha taslağı, pres sacı üzerine yerleştirildikten sonra, önce dış tabaka yongaları el ile homojen bir şekilde serilmiş, ardından orta tabaka ve ikinci dış tabaka yongaları serilmiştir. Serme işleminden sonra taslak, şekillendirme çerçevesi büyüklüğünde bir tabla ile bastırılarak soğuk pres uygulaması gerçekleştirilmiştir. Ardından taslak pres sacına yapışmayı önleyici yağlı kağıt ve üst pres sacı yerleştirilerek sıcak prese yüklenmiştir. Şekil 2'de sırası ile tutkallama, serme, taslak levha ve sıcak pres görüntüleri verilmiştir.

Soğuk presten çıkan levha taslakları, elektrikle ısıtılan tek katlı hidrolik pres (sıcak) ile preslenmiştir (Şekil 2). Her levha türünden 2'şer adet olmak üzere toplam 16 adet levha üretilmiştir. Pres sıcaklığı $150{ }^{\circ} \mathrm{C}$, pres süresi 7 dakika ve pres basıncı $25 \mathrm{~kg} \mathrm{~cm}^{-2}$ olarak uygulanmıştır. Sicak presten alınan levhalar, TS 642 ISO 554 (1997) standardına uygun olarak $20 \pm 2{ }^{\circ} \mathrm{C}$ sıcaklık ve $\% 65 \pm 5$ bağıl nem şartlarındaki iklimlendirme odasında 1 ay süre ile bekletilmiş ve levhalardan testler için gerekli deney örnekleri hazırlanmıştır.

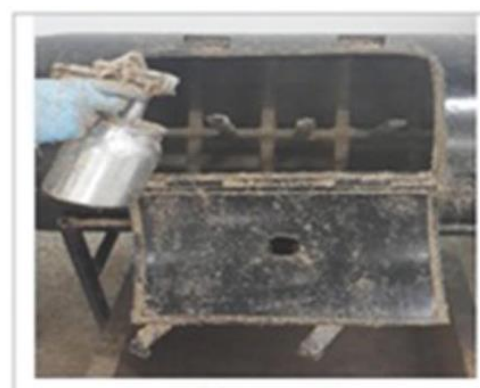

Tutkallama

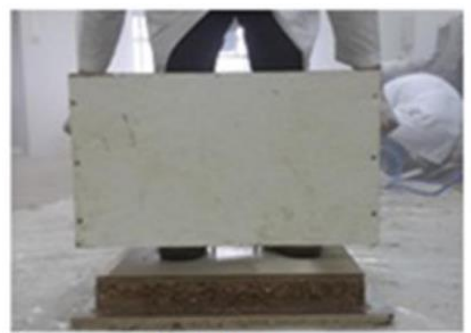

Soğuk pres

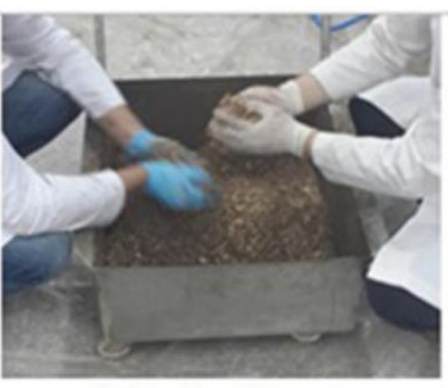

El ile karıştmma

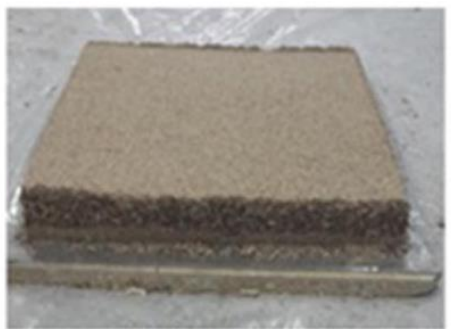

Taslak levha

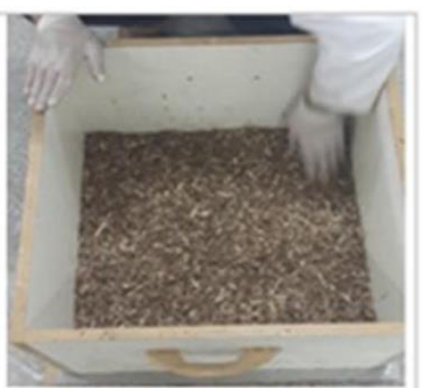

Serme (orta tabaka)

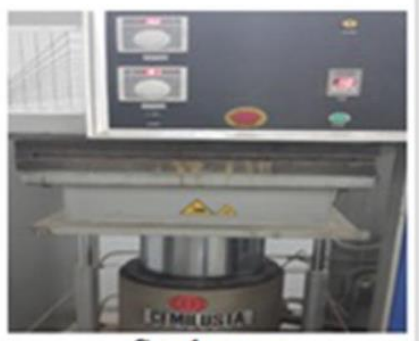

Sicak pres

Şekil 2. Deneme levhası üretim aşamaları. 


\section{Vida Tutma Gücü}

Yüzeye ve kenara dik vida tutma gücü değerleri EN 320 (2011) standardına göre belirlenmiştir. Deneyler, $75 \times 75 x$ levha kalınlığında $(\mathrm{mm})$ hazırlanan 15 adet test örneği üzerinde gerçekleştirilmiştir. Deney örnekleri sabit kütleye ulaşıncaya kadar iklimlendirme odasında bekletilmiştir. Deney örneklerinin köşegenleri çizilerek orta noktaları tespit edilmiştir. Daha sonra bu noktalardan $2.7 \mathrm{~mm}$ çapında $19 \pm 1 \mathrm{~mm}$ derinliğinde kılavuz delikleri açılmıştır. Deneyde kullanılan vidalar yıldız başlıklı olup, $38 \mathrm{~mm}$ uzunluğunda ve $4.2 \mathrm{~mm}$ çapındadır. Vidalar, levhanın bir yüzeyine ve iki komşu kenarına dik gelecek şekilde kılavuz deliklerine yerleştirilmiştir. Vida girme derinliği $15 \pm 0.5 \quad \mathrm{~mm}$ 'dir. Vida çekme direncinin hesaplanmasında aşağıdaki Eşitlik 1.'den yararlanılmıştır.

$f=\frac{F_{\max }}{d x l_{p}}$

Burada, $f$ vida tutma gücünü $\left(\mathrm{N} \mathrm{mm}^{-2}\right)$, Fmax vidanın çıkma anındaki maksimum yükü $(\mathrm{N}), \mathrm{d}$ vida çapını $(\mathrm{mm})$, Ip ise vida girme derinliğini $(\mathrm{mm})$ ifade etmektedir.

\section{Isı Illetkenlik Değeri}

Kontrol ve test örneklerinin Isı iletkenlik ölçümleri Düzce Üniversitesi Bilimsel ve Teknolojik Araştırmalar Uygulama ve Araştırma Merkezi Laboratuvarlarında (DÜBIT), yapılmıştır. Isı iletkenlik ölçümleri, ASTM D7984-16 (2016) standardına göre gerçekleştirilmiştir. Ölçümler, 50x50x levha kalınlığı $(\mathrm{mm})$ boyutlarındaki deney örneklerinden 10 tekrarlı olarak yapılmıştır. Iletkenlik ölçümlerinde, CTHERM TCI model termal iletkenlik katsayısı ölçüm cihazı kullanılmıştır (Şekil 3). Cihaz modifiye edilmiş geçici düzlem kaynak (Modified Transient Plane Source-MTPS) tekniği prensibine göre çalışmaktadır. Cihazla 0-10 $\mathrm{W} \mathrm{m}^{-}$ ${ }^{1} \mathrm{~K}^{-1}$ aralığında ısı iletkenliğe sahip malzemelerin ölçümü gerçekleştirilebilmektedir. Ölçümü yapılacak malzemenin uygun bir yüzeyi (düz ve pürüzsüz) cihazın sensörü ile temas ettirilir ve cihaz sensör ile numune arasındaki sıcaklık etkileşiminden yola çıkarak malzemenin ISI iletkenlik katsayısını $\mathrm{W} \mathrm{m}^{-1} \mathrm{~K}^{-1}$ cinsinden belirlemektedir (Anonim 2016b).

Deneme levhalarına ait ısı iletkenlik katsayısı değerleri aşağıdaki Eşitlik 2. yardımı ile hesaplanmıştır. $k=\frac{q \cdot \ln \left(t_{2} / t_{1}\right)}{4 \pi\left(T_{2}-T_{1}\right)} \quad\left(W m^{-1} K^{-1}\right)$

Burada, $k$ ISı iletkenlik değerini, q örnek kesit alanından geçen Isı akısını, $t_{2} / t_{1}$ ölçülen zaman aralığı, $T_{2}-T_{1}$ ölçüm cihazının iki yüzeyi arasındaki sıcaklık farkını ifade etmektedir.

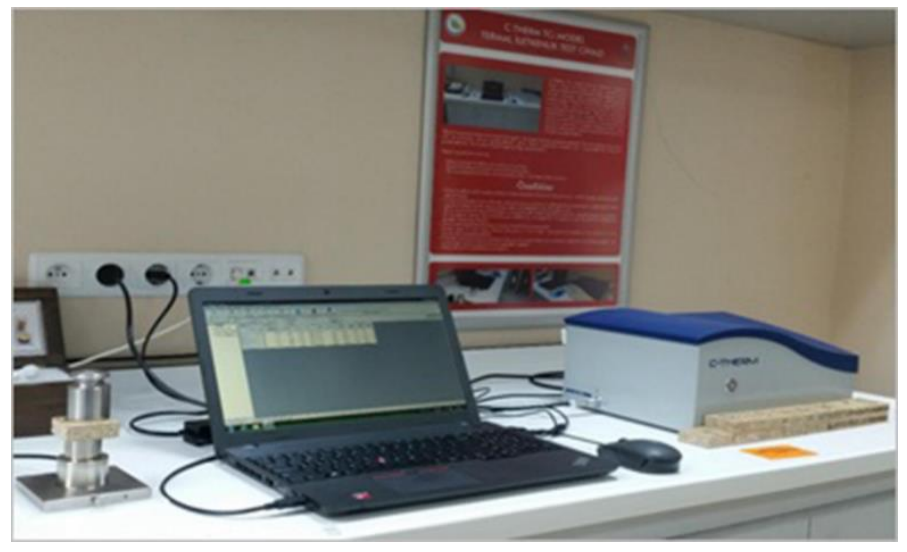

Şekil 3. Isı iletkenlik ölçüm cihazı.

\section{Verilerin Değerlendirilmesi}

Deneysel çalışmalar sonunda elde edilen verilerin değerlendirilmesinde SPSS 16 istatistik paket programı kullanılmıştır. Çalışmada tek faktör ve ikiden fazla deney grubu söz konusu olduğundan bütün deneylerde basit varyans analizi uygulanmış olup değişkenlerin etkili olup olmadığı belirlenmiştir. Farklılıkların anlamlı çıkması halinde ise Duncan testi uygulanmıştır. Homojenlik göstermeye örnekler istatistikî değerlendirmeye alınmamıştır.

\section{BULGULAR ve TARTIŞMA}

Deneme levhaları üzerinde yapılan levha yüzeyine dik ve paralel yöndeki vida tutma gücü değerleri ile homojenlik grupları Çizelge 2'de, basit varyans analiz sonuçları ise Çizelge 3 'te verilmiştir. Her bir levha türüne ait ortalama yüzeye dik ve paralel vida tutma güçleri arasındaki farklılığın istatistiksel olarak anlamlı olduğu anlaşılmıştır $(p<0.05$, Çizelge 3$)$. Bu nedenle yapılan Duncan testi sonuçlarına göre $A, B, C$ ve $D$ grubu levhaları, $E, F$ ve $E, G$ grubu levhaların yüzeye dik vida tutma güçleri arasında istatistiksel olarak fark bulunmamıştır. $\mathrm{H}$ grubu levhalar ise diğer tüm gruplardan farklı bulunmuştur. Yüzeye paralel vida tutma gücüne ait istatistiksel sonuçlar yüzeye dik yöndeki analizlere benzer sonuçlar vermiştir. En 
yüksek yüzeye dik vida tutma gücü \%100 odundan üretilmiş $A$ grubu levhalarda $\left(12.3 \mathrm{~N} \mathrm{~mm}^{-2}\right)$ elde edilmiş iken paralel yönde ise B grubunda tespit edilmiştir (9.8 N $\mathrm{mm}^{-2}$ ).

Çizelge 2. Levhalara ait yüzeye dik ve paralel yönde vida tutma gücü değerleri $\left(\mathrm{N} \mathrm{mm}^{-2}\right)$

\begin{tabular}{|c|c|c|c|c|c|c|}
\hline Levha türü & \multicolumn{3}{|c|}{ Yüzeye Dik } & \multicolumn{3}{|c|}{ Yüzeye Paralel } \\
\hline & \multicolumn{2}{|r|}{$V d$} & HG & \multicolumn{2}{|l|}{$V p$} & HG \\
\hline A Grubu & \multicolumn{2}{|c|}{$12.31(1.05)^{*}$} & $a^{* *}$ & \multicolumn{2}{|c|}{$9.65(1.26)$} & bc \\
\hline B Grubu & \multicolumn{2}{|c|}{$12.03(1.14)$} & a & \multicolumn{2}{|c|}{$9.76(1.25)$} & bc \\
\hline C Grubu & \multicolumn{2}{|c|}{$11.74(1.98)$} & $a$ & \multicolumn{2}{|c|}{$9.58(1.24)$} & bc \\
\hline D Grubu & \multicolumn{2}{|c|}{$11.51(1.84)$} & $a$ & \multicolumn{2}{|c|}{$9.60(1.43)$} & bc \\
\hline E Grubu & \multicolumn{2}{|c|}{$10.27(1.26)$} & bc & \multicolumn{2}{|c|}{$8.12(1.01)$} & $d$ \\
\hline F Grubu & \multicolumn{2}{|c|}{$10.46(1.33)$} & b & \multicolumn{2}{|c|}{$7.66(1.48)$} & de \\
\hline G Grubu & \multicolumn{2}{|c|}{$9.26(1.26)$} & c & \multicolumn{2}{|c|}{$6.46(0.95)$} & fg \\
\hline H Grubu & \multicolumn{2}{|c|}{$6.99(1.47)$} & ef & \multicolumn{2}{|c|}{$5.71(1.28)$} & g \\
\hline \multirow{2}{*}{\multicolumn{7}{|c|}{$\begin{array}{l}\text { *: Parantez içindeki değerler standart sapmayı ifade eder, }{ }^{* *} \text { : Satırda ve sütunda aynı harfler ile } \\
\text { dik yönde vida çekme direnci, } V p \text { : Yüzeye paralel yönde vida çekme direnci, HG: Homojenlik gr } \\
\text { Çizelge 3. Deneme levhalarının vida tutma gücüne ait basit varyans analiz sonuçları. }\end{array}$}} \\
\hline & & & & & & \\
\hline Test Türü & Varyans kaynağı & Kareler toplamı & Serbestlik derecesi & Kareler ortalaması & F-Hesap & Önem derecesi \\
\hline \multirow[t]{3}{*}{ Yüzeye Dik Vida Tutma Gücü } & Gruplar arası & 331.0 & 7 & 47.3 & 22.550 & 0.000 \\
\hline & Gruplar içi & 234.8 & 112 & 2.1 & & \\
\hline & Toplam & 565.8 & 119 & & & \\
\hline \multirow[t]{3}{*}{ Yüzeye Paralel Vida Tutma Gücü } & Gruplar arası & 267.0 & 7 & 38.1 & 24.391 & 0.000 \\
\hline & Gruplar içi & 175.1 & 112 & 1.6 & & \\
\hline & Toplam & 442.1 & 119 & & & \\
\hline \multirow[t]{3}{*}{ Isı İletkenlik Direnci } & Gruplar arası & 0.011 & 7 & 0.002 & 12.244 & 0.000 \\
\hline & Gruplar içi & 0.009 & 72 & 0.000 & & \\
\hline & Toplam & 0.020 & 79 & & & \\
\hline
\end{tabular}

Genel olarak, orta tabakaya ilave edilen kompost miktarının artışına veya odun yonga oranındaki azalmaya bağlı olarak hem paralele hem de dik yönde vida tutma gücünde azalmalar tespit edilmiştir (Şekil 4). Benzer sonuçlar, Hint yıllık bitkisi (Ricinus communis L.) ilaveli ve üre formaldehit tutkalı kullanılarak üretilmiş yongalevhalarda da tespit edilmiştir (Grigoriou ve Ntalos 2001). Başka bir çalışmada odun yongası ve odun lifi ilavesinin odun polimer kompozitine ait vida tutma gücünde artışlara sebep olduğu ifade edilmektedir (Gökalp 2006). Ayçiçeği kabuklarından üretilmiş yongalevhaların bazı fiziksel ve mekanik özelliklerinin araştırıldığı bir çalışmada, kabuk oranının azalmasına bağlı olarak levha yüzeyine dik vida tutma gücünde önemli derecede artışlar olduğu belirtilmiştir (Cosereanu ve ark. 2014).
Kompost atığı ilavesindeki artışa bağıı olarak vida tutma gücü değerlerinde önemli azalmalar meydana gelmiştir. Ancak, F grubu levhalara ait yüzeye dik vida çekme değerlerinde bir miktar artış gözlenmesine karşın, bir önceki grup ile arasındaki fark istatistiksel olarak önemli bulunmamıştır. Benzer bir durum ise paralel yönde $B$ ve $D$ grubu levhalarda elde edilmiştir. Bu durum vida tutma gücüne ait genel eğilim üzerinde önemli bir etkiye sebep olmamakla birlikte, levha taslağının el ile serilmesi esnasında yongaların heterojen olarak serilmesinden kaynaklandığı düşünülmektedir (Çakır 2012). 


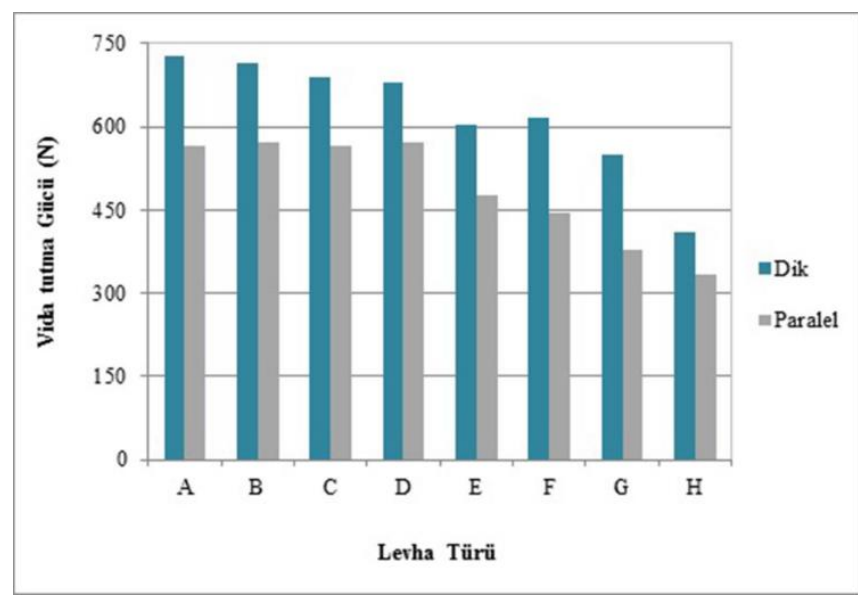

Şekil 4. Deneme levhalarına ait yüzeye dik ve paralel vida tutma gücü değerleri $(\mathrm{N})$

Endüstriyel odun yongası ve orta tabakası kompost atığı ilaveli yonga levhaların, en düşük vida tutma gücü orta tabakası \% 100 kompost atığı bulunan $\mathrm{H}$ grubu levhalarda elde edilmiştir (Şekil 4). Bu değeler sırası ile yüzeye dik ve paralel vida tutma gücü için 441 ve $334 \mathrm{~N}$ olarak bulunmuştur. Bektaş ve ark. (2005) ayçiçeği sapı kullanarak üretmiş oldukları yongalevhalara ait en düşük vida tutma gücü değerleri yine \% 100 oranında Ayçiçek sapı kullandıkları deneme levhalarında elde etmişlerdir (826 ve 539 N). Ayrıca, yonga karışımındaki Ayçiçek sapı oranının artması ile deneme levhalarının vida tutma değerlerinin azaldığını ifade etmişlerdir.

Deneme levhalarına ait vida tutma gücü değerlerindeki azalmalar özellikle orta tabaka kompost katılım oranı \% 30 (E grubu) ve üzerinde uygulanan levhalarda belirgin olarak ortaya çıkmıştır. Bütün uygulamalarda yüzeye dik vida tutma gücü değerleri, levha yüzeyine paralel tutma gücünden daha yüksek değerler vermiştir. Literatürde yapılan farklı araştırmalarda levha yüzeyine paralel yönde vida tutma gücünün $360 \mathrm{~N}$ olması gerektiği ifade edilmektedir (BS 2604 1970; Nemli ve ark. 2004; Bektas ve ark. 2005). H grubu levhaların levha yüzeyine paralel vida çekme gücü hariç diğer üretilen tüm levhalar standardın belirttiği minimum sınır değerini karşılamaktadır.

Üretilen deneme levhalarına ait Isı iletkenlik değerleri ile homojenlik grupları Çizelge 4'te, bu verilere ait basit varyans analiz sonuçları ise Çizelge $3^{\prime}$ te verilmiştir.
Çizelge 4. Deneme levhalarına ait ısı iletkenlik değerleri $\left(\mathrm{W} \mathrm{m}^{-1} \mathrm{~K}^{-1}\right)$

\begin{tabular}{ccccc}
\hline Levha türü & $k$ & HG & Min. & Mak. \\
\hline A Grubu & $\begin{array}{c}0.099 \\
(0.019)^{*}\end{array}$ & $b^{* *}$ & 0.079 & 0.121 \\
\hline B Grubu & $\begin{array}{c}0.092 \\
(0.013)\end{array}$ & ab & 0.079 & 0.108 \\
\hline C Grubu & $\begin{array}{c}0.099 \\
(0.003)\end{array}$ & b & 0.093 & 0.103 \\
\hline D Grubu & $\begin{array}{c}0.086 \\
(0.010)\end{array}$ & a & 0.074 & 0.097 \\
\hline E Grubu & $\begin{array}{c}0.091 \\
(0.015)\end{array}$ & ab & 0.073 & 0.106 \\
\hline F Grubu & $\begin{array}{c}0.120 \\
(0.008)\end{array}$ & c & 0.110 & 0.129 \\
\hline G Grubu & $\begin{array}{c}0.112 \\
(0.005)\end{array}$ & c & 0.104 & 0.118 \\
\hline H Grubu & $\begin{array}{c}0.086 \\
(0.004)\end{array}$ & a & 0.081 & 0.091 \\
\hline
\end{tabular}

k: ortalama Isı iletkenlik değeri, HG: homojenlik grubu. Min.: Minimum değer, Mak.: Maksimum değer.

Levha gruplarına ait Isı iletkenlik değerleri 0.086-0.120 W $\mathrm{m}^{-1} \mathrm{~K}^{-1}$ arasında değiştiği tespit edilmiştir. Buna karşılık, TS 825 (2013)'e göre ahşap ve ahşap mamullerinin izolasyon levhası kullanımı durumunda yatık yongalı yongalevhaların ısı iletkenlik değerlerini maksimum 0.130 W $\mathrm{m}^{-1} \mathrm{~K}^{-1}$ olarak ön görmüştür. Yapılan deneyler sonucunda, orta tabakası kompost atığı ilaveli tüm deneme levhalarına ait ısı iletkenlik değerleri standardın belirlediği üst sınır değerinin altında bulunmuştur. İzolasyon levhası olarak en iyi sonuçlar orta tabakasında \%100 kompost atığı kullanılan H grubu levhalarda elde edilmiştir. Lignoselülozik materyallerin izolasyon levhası olarak kullanımı üzerine bir çok araştırma yapılmıştır. Bu çalışmalara göre ISı iletkenlik değerleri, dişbudak odununda $0.1549 \mathrm{~W} \mathrm{~m}^{-1} \mathrm{~K}^{-1}$, Uludağ göknarında $0.1128 \mathrm{~W}$ $\mathrm{m}^{-1} \mathrm{~K}^{-1}$, kavakta $0.1146 \mathrm{~W} \mathrm{~m}^{-1} \mathrm{~K}^{-1}$, yatık yongalı levhalarda $0.1783 \mathrm{~W} \mathrm{~m}^{-1} \mathrm{~K}^{-1}, \mathrm{MDF}^{\prime}$ de $0.1998 \mathrm{~W} \mathrm{~m}^{-1} \mathrm{~K}^{-1}$, HDF levhalarda ise $0.2065 \mathrm{~W} \mathrm{~m}^{-1} \mathrm{~K}^{-1}$ olarak ifade edilmektedir (Örs ve Şenel 1999; Uysal ve ark. 2011; Özdemir ve ark. 2013).

Dukarska et al. (2016) yaptıkları bir çalışmada, Kolza saplarının yongalevha üretimine uygunluğu üzerine çalışmışlardır. Çalışma sonuçları, yıllık bitkilerin kullanıldığı levhaların farkı bağı nem ortamlarındaki su absorbsiyon ve desorpsiyon dirençlerinin düşük olduğunu ancak, normal levhalara göre termal iletkenliklerinin ise daha yüksek olduğunu göstermiştir. 
Levha gruplarına ait ortalama Isı iletkenlik değerleri arasındaki farklılı̆ın istatistiksel olarak anlamlı olduğu belirlenmiştir (Çizelge 3). Bu nedenle yapılan Duncan testi sonuçlarına göre orta tabakada kullanılan kompost atığı oranı ile levha ısı iletkenlik değerleri arasında pozitif veya negatif yönlü bir doğrusal ilişki bulunmamıştır. A, B, C ve E grubu levhalara ait Isı iletkenlik değerleri arasında istatistiksel olarak bir fark yoktur $(p<0.05)$. En yüksek ısıl iletkenlik değerleri $F\left(0.120 \mathrm{~W} \mathrm{~m}^{-1} \mathrm{~K}^{-1}\right)$ ve $\mathrm{G}$ grubu $(0.112$

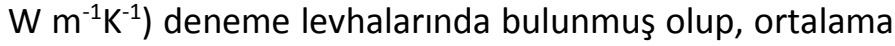
ISı iletkenlik değerleri bakımından aralarında istatistiksel olarak bir fark yoktur (Çizelge 4; $p<0.05$ ).

Yöntem bölümünde, hedeflenen levha yoğunluğunun $0.630 \mathrm{gr} \mathrm{cm}^{-3}$ olduğu ifade edilmiştir. Üretilen levhalarda tespit edilen ortalama yoğunluk değeri ise $0.628 \mathrm{gr} \mathrm{cm}^{-3}$ olarak bulunmuştur. Her bir levha grubuna ait yoğunluk değerleri arasında istatistiksel olarak önemli bir fark yoktur. Bilindiği üzere ISI iletkenlik değeri önemli derecede yoğunluğa bağlıdır (Kol ve Altun 2009; Xu et al. 2004; Dukarska et al. 2016). Bu nedenle orta tabakası kompost atığı ilaveli levhalara ait Isı iletkenlik değerleri arasında önemli bir farkın tespit edilememesi, levhaların yoğunluk değerlerinin birbirine yakın olmasından kaynaklandığı düşünülmektedir.

Literatürde düşük yoğunluklarda üretilen yıllık bitki ilaveli yonga ve lif levhalarda daha düşük ISI iletkenlik değerlerine ilişkin birçok çalışma bulunmaktadır. Örneğin Ihnat et al. (2015) ve Ihnat and Lübke (2015), çeşitli miktarlarda buğday sapı ilaveli $0,250 \mathrm{~g} \mathrm{~cm}^{-3}$ yoğunluktaki lif levhalarda Isı iletkenlik değerlerinin 0.050-0.064 W m${ }^{1} \mathrm{~K}^{-1}$ arasında değiştiğini ifade etmektedir. Benzer sonuçlar pirinç sapı kullanılarak üretilmiş levhalarda da elde edilmiştir (Wei et al. 2015).

\section{SONUÇ}

Yapılan çalışmada, levhaların orta tabakasına ilave edilen kompost atı̆̆ı oranının artmasına bağlı olarak yongalevhaların yüzeyine dik ve paralel yöndeki vida tutma gücü değerlerinde önemli azalmalar meydana gelmiştir. Üretilen levhaların yüzeye dik yöndeki vida tutma gücü değerleri, levha yüzeyine paralel vida tutma gücü değerlerinde daha yüksek bulunmuştur. Üretilen yonga levhaların ISı iletkenlik değerleri arasında istatistiksel olarak farklılıkların bulunmasına rağmen, bütün levhalara ait ISı iletkenlik değerleri standardın (TS 825) belirlediği üst sınır değerlerinin altında olduğu görülmüştür. Ayrıca en yüksek ısı iletkenlik değerleri $F$ ve $G$ grubu yongalevhalarda çıkmıştır.

Orta tabakası tamamen kompost atığından üretilmiş levhalardan sadece $\mathrm{H}$ grubu levhalara ait yüzeye paralel vida tutma gücü standartların belirtmiş olduğu alt sınır değerleri karşılamamıştır. Bu nedenle \% 100 kompost atığından üretilmiş yongalevhaların izolasyon levhası olarak kullanılmasının daha uygun olacağı düşünülmektedir. Bu levhalar özellikle, binaların iç mekân duvar ve taban bölmelerinde, çatı altlarında ve prefabrik evlerde standartlarda belirtilen kriterlere uygun olarak kullanılabilecektir. Ayrıca bu tür levhaların daha düşük yoğunluklarda üretilmesi ile yüksek izolasyon özelliğine sahip levhaların üretilmesi de mümkün olabilir.

\section{TEŞEKKÜR}

Bu çalışma, Düzce Üniversitesi BAP-2016.02.03.432 numaralı Bilimsel Araştırma Projesiyle desteklenmiştir.

\section{KAYNAKLAR}

Anonim (2016a). https://biruni.tuik.gov.tr/bitkiselapp/bitkisel.zul. (Erişim Tarihi: Aralık 2016).

Anonim (2016b). http://www.dutap.duzce.edu.tr/5167-sayfa-termaliletkenlik-test-cihazi. (Erişim Tarihi: Aralık 2016).

ASTM D7984-16 (2016). Standard test method for measurement of thermal effusivity of fabrics using a Modified Transient Plane Source (MTPS) instrument. ASTM International, West Conshohocken, PA.

Bal BC, Gündeş Z, Akçakay E (2015). Kavak, kayın ve okaliptüs kaplamaları ile üretilen kontrplakların vida tutma direncinin araştırılması. KSU Mühendislik Bilimleri Dergisi 18(2):77-83.

Bektaş I, Güler C, Kalaycıoğlu H (2002). Ayçiçeği (Helianthus annuus L.) saplarından üre-formaldehit tutkalı ile yongalevha üretimi. Kahramanmaraş Sütçü İmam Üniversitesi, Fen ve Mühendislik Dergisi 5(2):49-56.

Bektaş I, Güler C, Kalaycıoğlu H, Mengeloglu F, Nacar M (2005). The manufacture of particleboards using sunflower stalks (Helianthus annuus L.) and poplar wood (Populus alba L.). Journal of Composite Materials 39(5):467-473.

BS 2604 (1970). Resin Bonded Wood Chipboard, British Standart Institution, London.

Cosereanu CN, Brenci LMN, Zeleniuc OI, Fotin AN (2014). Effect of particle size and geometry on the performance of single-layer and three-layer particleboard made from sunflower seed husk. BioResources 10(1):1127-1136. 
Çakır G (2012). Bor katkılı zeytin karasuyu ile emprenye edilmiş bağ budama artıklarından üretilmiş yonga levhaların fiziksel, mekanik ve çürüklük direncine olan etkisinin belirlenmesi. Muğla Üniversitesi, Fen Bilimleri Enstitüsü, Yüksek Lisans Tezi, Muğla, $117 \mathrm{~s}$.

Dukarska D, Czarnecki R, Dziurka D, Mirski R (2016). Construction particleboards made from rapeseed straw glued with hybrid pMDI/PF Resin. Holz als Roh- und Werkstoff 75(2):175-184.

Eren E, Pekşen A (2016). Türkiye'de kültür mantarı sektörünün durumu ve geleceğine bakış. Türk Tarım - Gıda Bilim ve Teknoloji Dergisi 4(3):189-196.

Gökalp E (2006). Odunsu materyal kullanımının polyester esaslı (mermerit) levhaların bazı teknolojik özelliklerine etkisi, Karadeniz Teknik Üniversitesi, Fen Bilimleri Enstitüsü, Yüksek Lisans Tezi, Trabzon, 130s.

Grigoriou AH, Ntalos GA (2001). The potential use of Ricinus communis L. (Castor) stalks as a lignocellulosic resource for particleboards. Industrial Crops and Products 13:209-218.

Ihnat V, Lübke $H$ (2015). Straw pulp as a secondary lignocellulosic raw material and its impact on properties of insulating iberboards. Part II. Preparation of insulated iberboards with straw content. Wood Research 60(2):235-246.

Ihnat V, Boruka V, Babiak M, Lübke H, Schwartz J (2015). Straw pulp as a secondary lignocellulosic raw material and its impact on properties of insulating iberboards. Part III. Preparation of insulated iberboards from separately milled lignocellulosic raw materials. Wood Research, 60(3):441-450.

$\mathrm{Kol} \mathrm{H}$, Altun S (2009). Effect of some chemicals on thermal conductivity of impregnated laminated veneer lumbers bonded with poly(vinyl acetate) and melamine-formaldehyde adhesives. Drying Technology 27:1010-1016.

Nemli G, Kalaycıoğlu H (1999). Melamin emdirilmiş kâğıtlarla kaplamanın yongalevha teknik özelliklerine etkileri. Turkish Journal of Agriculture and Forestry 23, Ek Sayı 1:25-31.
Nemli G, Kalaycıoğlu H, Akbulut T (2004). Pres çeşidinin yonga levha teknik özellikleri üzerine etkisi. Kafkas Üniversitesi Artvin Orman Fakültesi Dergisi 5(2):89-95.

Örs Y, Özen R, Doğanay S (1998). Mobilya üretiminde kullanılan ağaç malzemelerin vida tutma dirençleri. Turkish Journal of Agriculture and Forestry 22:29-34

Örs Y, Şenel A (1999). Bazı ahşap ve ahşap kökenli malzemelerin ISı iletkenlik katsayıları. Turkish Journal of Agriculture and Forestry 23, Ek Sayı 1:239-245.

Özdemir C (2010). Mantar yetiştiriciliği. Samsun II Tarım Müdürlüğü Çiftçi Eğitimi ve Yayım Şubesi, 1-20.

Smardzewski J, Klos R (2011). Modelling of joint substitutive rigidity of board elements. Annals of Warsaw University of Life Science, Forestry and Wood Technology 73:7-15.

Sonderegger W, Niemz P (2009). Thermal conductivity and water vapour transmission properties of wood-based materials. European Journal of Wood and Wood Products 67(3):313-321.

Strangh $L$ (1993). The future raw material balance. Xilon-International 6(63):28-32.

Wei K, Lv Ch, Chen M, Zhou X, Dai Z, Shen D (2015). Development and performance evaluation of on a new thermal insulation material from rice straw using high frequency hot-pressing. Energy and Buildings 87(1):116-122.

Xu J., Sugawara R., Widyorini R., Han G., Kawai S. (2004). Manufacture and properties of low-density binderless particleboard from kenaf core, Journal of Wood Science, 50: 62-67.

Youngquist JA, English BE, Spelter H, Chow P (1993). Agricultural fibers in composition panels. In: Proceedings of the 27th international Particleboard: Composite materials symposium, W.S.U. Pullman, Washington, pp. 133-152.

Yu ZT, Xu X, Fan LW, Hu YC, Cen KF (2011). Experimental measurements of thermal conductivity of wood species in China: efects of density, temperature, and moisture content. Forest Products Journal 61(2):130-135. 